Research Article

\title{
Anticonvulsant profile of nardostachys jatamansi roots in albino rats
}

\author{
Purushotham K. ${ }^{1 *}$, Basavanna PL $^{2}$
}

${ }^{1}$ Department of Pharmacology, Sri Siddhartha medical college, Tumakuru- 527 107, Karnataka, India,

${ }^{2}$ Department of Pharmacology, Mysore Medical College and Research Institute, Mysore, India

Received: 18 February 2016

Accepted: 21March 2016

\section{*Correspondence to:}

Dr. Purushotham K.,

Email: dr.arian18@gmail.com

Copyright: (C) the author(s), publisher and licensee Medip Academy. This is an openaccess article distributed under the terms of the Creative Commons Attribution NonCommercial License, which permits unrestricted noncommercial use, distribution, and reproduction in any medium, provided the original work is properly cited.

\begin{abstract}
Background: Epilepsy is a common neurological disorder. Despite the massive scale of the problem and much research, epilepsy remains poorly understood. Most of the currently used antiepileptic drugs have some neurotoxic effects, cognitive deficits and teratogenic effects, which decrease their clinical utility and up to $30 \%$ of patients are still refractory to treatment. The present study is undertaken to evaluate the anticonvulsant activity of ethanolic extract of nardostachys jatamansi root in albino rats.

Methods: Albino rats (150-200 gms) of male sex were randomly selected, from central animal facility. They were divided into 5 groups(per model) of 6 rats each, control group-propylene glycol $0.5 \mathrm{ml}$, standard group-sodium valproate $(300 \mathrm{mg} / \mathrm{kg})$, dose 1-ethanolic extract of nardostachys jatamansi roots (100 $\mathrm{mg} / \mathrm{kg})$, dose 2-ethanolic extract of nardostachys jatamansi roots $(200 \mathrm{mg} / \mathrm{kg})$ and dose 3-ethanolic extract of nardostachys jatamansi roots $(400 \mathrm{mg} / \mathrm{kg})$. The anti-convulsant activity was screened using maximal electroshock seizure model and pentylenetetrazole model. Results were analysed by ANOVA followed by post hoc Fisher's LSD test.

Results: The ethanolic extract of nardostachys jatamansi roots at the dose of $400 \mathrm{mg} / \mathrm{kg}$ has shown significant anticonvulsant activity in maximal electroshock seizure (MES) model. Whereas, in pentylenetetrazole induced seizure model, the ethanolic extract of nardostachys jatamansi roots has shown significant anticonvulsant activity at the dose of $200 \mathrm{mg} / \mathrm{kg}$ and $400 \mathrm{mg} / \mathrm{kg}$ body weight.

Conclusions: The anticonvulsant activity of ethanolic extract of nardostachys jatamansi roots was less when compared to Sodium Valproate in Maximal Electro Shock model. Whereas, in Pentylenetetrazole induced seizure model, anticonvulsant activity of ethanolic extract of nardostachys jatamansi roots was comparable to sodium valproate.
\end{abstract}

Keywords: Epilepsy, MES model, Nardostachys jatamansi, Pentylenetetrazole, Sodium valproate.

\section{INTRODUCTION}

Epilepsy is one of the most frequent neurodegenerative diseases. ${ }^{1}$ Epilepsy is a condition in which a person has recurrent seizures. Seizure can defined as an abnormal, disorderly discharging of nerve cells of brain; resulting in a temporary disturbance of motor, sensory, or mental function. ${ }^{2}$ Epilepsy is a major neurological disorder and up to $5 \%$ of the world population develops epilepsy in their lifetime. ${ }^{3}$ Annual incidence of epilepsy in India is approximately 2.7/100,000 per year. ${ }^{4}$ Epilepsy is not curable, but can be controlled with anticonvulsant which prevent the seizures or lessen their intensity. The current therapy of epilepsy with modern antiepileptic drugs is associated with side effects, dose-related and chronic toxicity, as well as teratogenic effects, and approximately $30 \%$ of the patients continue to have seizures with current antiepileptic drugs therapy.,

There is still a need for an ideal antiepileptic agent with properties like broad spectrum activity, rapid onset of action, least side effects, good oral bioavailability and low costs. The discovery of novel antiepileptic drugs relies upon the preclinical employment of animal models to establish efficacy and safety prior to the introduction 
of the antiepileptic drugs in human volunteers. ${ }^{7}$ Over the last few years, researches have aimed at identifying and validating plant derived substances for the treatment of various diseases. Interestingly, it is estimated that more than $25 \%$ of modern medicines are directly or indirectly derived from plants. ${ }^{8}$ Therefore there is growing interest in alternative approach for the treatment of seizures and the use of medicinal plants has gained popularity around the world. Hypericum perforatum, piper methysticum, actaea racemosa and erythrophleum ivorense are among plants that have been used to treat seizures. ${ }^{9}$

The advantages of indigenous medicinal treatment would include its complementary nature to the conventional treatment making latter safer, well tolerated and economical remedy for epilepsy. Nardostachys jatamansi DC (valerianaceae) is widely used in ayurvedic medicine. The essential oil obtained from the roots of jatamansi showed fungi toxic activity, antimicrobial, antifungal, hypotensive, antiarrhythmic and anticonvulsant activity. ${ }^{10}$ The information regarding the studies on jatamansi root are fewer and the studies on ethanolic extract of root on different anti-convulsant models are sparse, hence the present study has attempted to fill in the lacunae of this invaluable drug. Hence the present study was done to compare the anti-epileptic activity of jatamansi in comparison with the standard drug sodium valproate in electrically and chemically induced epileptic animal models.

\section{METHODS}

This study was conducted at a medical college in South India. Adult healthy male wistar rats weighing 150-200 g bodyweight, obtained from the central animal house facility were group housed in polyacrylic cages with each cage containing not more than four rats. The animals were maintained under standard laboratory conditions with natural dark and light conditions (12:12 hours) and ambient room temperature. They were allowed free access to standard pellet feed and tap water ad libitum. All procedures of the study were reviewed and approved by the institutional animal ethics committee. The care of animals was taken as per the guidelines of the committee for the purpose of control and supervision of experiments on animals (CPCSEA).

Collection and authentication of plant material - The plant was obtained from Gadgil Vanoushadhi Sangrah, Belgaum, which was identified and authenticated by a botanist.

Preparation of ethanolic extract of nardostachys jatamansi- The dried roots of nardostachys jatamansi was coarsely powered. 50 grams of the powder was wrapped in a filter paper and put into a thimble with $500 \mathrm{ml}$ of $95 \%$ ethanol in a round bottom flask and subjected to soxhlation for 6-8 hours. Dark brown solution of extract with alcohol was collected. Dark brown paste like extract was obtained after evaporation of alcohol.

Drugs and chemicals-pentylenetetrazol and propylene glycol were obtained from sigma chemicals, Mumbai, Maharashtra, India. Sodium valproate was obtained from local pharmacy.

\section{Selection of the dose of toxicity}

Acute oral toxicity study was carried out as per OECD423 guidelines. ${ }^{13}$ A group of six wistar rats of either sex selected by randomly and were used for acute toxicity study. The extracts were administered orally at the dose level of $5 \mathrm{mg} / \mathrm{kg}$ body weight by gastric intubation to overnight fasted animals and observed for 14 days. If mortality was observed in 2 out of 3 animals, then the dose administered was assigned as toxic dose, but if mortality was observed in one animal, then the same dose was repeated again to verify the toxic dose. If mortality was not observed, the procedure was repeated for further higher doses such as 50, 300 and $2000 \mathrm{mg} / \mathrm{kg}$ body weight.

\section{Selection of dose of the extract}

The ethanolic extract of nardostachys jatamansi (EENJ) root was found to be non-toxic up to the dose of 2000 $\mathrm{mg} / \mathrm{kg}$ and did not cause any death, therefore it is considered as safe. The biological evaluation was carried out at $100 \mathrm{mg} / \mathrm{kg}, 200 \mathrm{mg} / \mathrm{kg}$ and $400 \mathrm{mg} / \mathrm{kg}$ dose levels. A total of 60 rats were used, which were equally divided for MES induced seizure and PTZ induced seizure model. Each model comprised of 5 groups with 6 rats each $(n=6)$. After over-night fasting, group I received 0.5 $\mathrm{ml} / 100 \mathrm{~g}$ of propylene glycol (control) and group II received sodium valproate $300 \mathrm{mg} / \mathrm{kg}$ (standard). Group III, group IV and group V received $100 \mathrm{mg} / \mathrm{kg}, 200$ $\mathrm{mg} / \mathrm{kg}$ and $400 \mathrm{mg} / \mathrm{kg}$ of ethanolic extract of nardostachys jatamansi root, respectively. The route of administration was intraperitoneal.

\section{Maximal electro shock (MES) induced seizure model}

On the day of experimentation, 60 minutes after administration of drug/vehicle, seizures were induced by delivering an electroshock $(50 \mathrm{~mA}$ at $50 \mathrm{~Hz}$ for $0.2 \mathrm{sec})$ by means of an electro convulsiometer (techno India) through a pair of ear clip electrodes. ${ }^{14}$ The animals were observed individually for 30 minutes from the time of electric shock applied for different phases of epileptic seizures. The various parameters recorded were tonic flexion of fore and hind limb, tonic extension of hind limb, clonus, stupor and post-ictal depression. The abolition of the hind limb tonic extension is taken as an index of anticonvulsant activity. 


\section{Pentylenetetrazole induced seizure model}

Sixty minutes after administration of drug/vehicle, animals were challenged with a convulsive dose of pentylenetetrazole $(80 \mathrm{mg} / \mathrm{kg}$ i.p) dissolved in distilled water. ${ }^{14}$ The time taken for the onset of convulsion (seizure latency), duration of convulsion and the mortality were noted (James JEP, et. Abolition of seizure onset was taken as an index of anticonvulsant activity.

\section{Statistical analysis}

The summary statistics was done by measuring range, mean and standard deviation. The test of significance was done using two way repeated measures, analysis of variance (ANOVA) at appropriate places. Analysis of variance was do ne to compare more than two groups at a time. Following ANOVA, fisher's least significant difference (LSD) test was done to compare mean of one group with mean of another group. $\mathrm{P}$-value: $\mathrm{P}$ is the probability rate at 0.05 level of significance for the corresponding degree of freedom $(\mathrm{P}<0.05$ is considered statistically significant).

\section{RESULTS}

The Effect of ethanolic extract of nardostachys jatamansi root on MES-induced seizures in wistar albino rats (Table 1).

Table 1: Effect of ethanolic extract of nardostachys jatamansi root on MES-induced seizures in wistar albino rats.

\begin{tabular}{|ll|lllll|}
\hline Group Treatment & $\begin{array}{l}\text { Tonic hind } \\
\text { limb flexion }\end{array}$ & $\begin{array}{l}\text { Tonic hind limb } \\
\text { extension }\end{array}$ & Clonus & Stupor & $\begin{array}{l}\text { Post-ictal } \\
\text { depression }\end{array}$ \\
\hline I & Control (propylene glycol i.p) & $3.80 \pm 0.28$ & $7.22 \pm 0.97$ & $10.83 \pm 2.80$ & $277.50 \pm 42.80$ & $255.00 \pm 53.89$ \\
\hline II & $\begin{array}{l}\text { Standard ( sodium valproate } 300 \\
\text { mg/kg i.p) }\end{array}$ & $8.60 \pm 1.09$ & $0.00 \pm 0.00$ & $12.60 \pm 0.87$ & $286.33 \pm 47.62$ & $303.00 \pm 25.84$ \\
\hline III & EENJ (100 mg/kg i.p) & $4.40 \pm 0.50$ & $7.15 \pm 0.60$ & $19.94 \pm 0.51$ & $112.33 \pm 5.50$ & $254.00 \pm 10.75$ \\
\hline IV & EENJ(200 mg/kg i.p) & $4.53 \pm 0.52$ & $6.10 \pm 0.40$ & $15.95 \pm 0.91$ & $105.83 \pm 3.91$ & $208.50 \pm 30.84$ \\
\hline V & EENJ(400 mg/kg i.p) & $5.02 \pm 1.10$ & $3.67 \pm 0.62$ & $11.50 \pm 0.36$ & $92.83 \pm 3.80$ & $114.16 \pm 9.13$ \\
\hline
\end{tabular}

Table 2: Effect of ethanolic extract of nardostachys jatamansi root on PTZ-induced seizure.

\begin{tabular}{|lllc|}
\hline Group & \multicolumn{1}{c}{ Treatment } & Seizure latency or onset (second) & Duration of myoclonic jerks (second) \\
\hline I & Control (propylene glycol i.p) & $222.17 \pm 16.23$ & $797.67 \pm 49.04$ \\
\hline II & Standard ( sodium valproate $300 \mathrm{mg} / \mathrm{kg}$ i.p) & $377.00 \pm 28.89$ & $442.50 \pm 18.71$ \\
\hline III & EENJ (100 mg/kg i.p) & $239.00 \pm 27.14$ & $773.17 \pm 69.70$ \\
\hline IV & EENJ(200 mg/kg i.p) & $334.67 \pm 20.70$ & $524.00 \pm 56.05$ \\
\hline V & EENJ(400 mg/kg i.p) & $372.50 \pm 25.09$ & $430.83 \pm 32.76$ \\
\hline
\end{tabular}

The tonic hind limb extension (THLE) phase was abolished in group II (standard group). When group I is compared with group III, the difference between mean of THLE is statistically not significant $(\mathrm{t}=0.051, \mathrm{p}>0.1)$. When group I is compared with group IV, the difference between mean of THLE is statistically not significant $(t=1.069, p>0.2)$. When group $I$ is compared with group $\mathrm{V}$, the difference between mean of THLE is statistically significant $(\mathrm{t}=3.03, \mathrm{p}<0.02)$. This shows that only group $\mathrm{V}$ $(400 \mathrm{mg} / \mathrm{kg})$ is having a statistically significant reduction in mean duration of THLE when compared to control group.

The effect of ethanolic extract of nardostachys jatamansi root on PTZ-induced seizure (Table 2).

When group I was compared with group II, there was a statistically significant prolongation in mean duration of seizure latency $(t=4.673, p<0.01)$. When group I was compared with group III, the prolongation in mean duration of seizure latency $(\mathrm{t}=4.673, \mathrm{p}<0.01)$ was statistically not significant $(\mathrm{t}=0.53, \mathrm{p}>0.6)$. When group I was compared with group IV, there was a statistically significant prolongation in mean duration of seizure latency $(\mathrm{t}=4.25, \mathrm{p}<0.01)$. When group I was compared with group $\mathrm{V}$, there was a statistically significant prolongation in mean duration of seizure latency $(t=5.01$, $\mathrm{p}<0.01$ ). This shows that at doses of $200 \mathrm{mg} / \mathrm{kg}$ and 400 $\mathrm{mg} / \mathrm{kg}$ of EENJ root, there were statistically significant prolongation in mean duration of seizure latency.

\section{DISCUSSION}

In the present study, the EENJ root at a dose of 400 $\mathrm{mg} / \mathrm{kg}$ reduced the duration of tonic hind limb extension phase in MES induced seizure, which was statistically significant. On the other hand, when the convulsive challenge was made with PTZ, there was a statistically significant prolongation of seizure latency at doses of 200 $\mathrm{mg} / \mathrm{kg}$ and $400 \mathrm{mg} / \mathrm{kg}$. The findings are in contradiction 
to previously published reports on the antiepileptic effect of this plant. A study anticonvulsant and neurotoxicity profile of nardostachys jatamansi in rats by Rao VS suggested that the ethanolic extract of nardostachys jatamansi root, to be effective only in MES induced seizure model whereas ineffective in PTZ induced seizure model. $^{15}$

The present study indicated effectiveness in both MES induced and PTZ induced seizure model. However, the standard drug and assessment parameters were different in both these studies. Other studies have found EENJ root to inhibit electroshock convulsions, increase in the levels of central monoamines and inhibitory amino acids, including a change in the levels of serotonin, 5-hydroxyindole acetic acid, gamma-amino butyric acid, and taurine in rat brain. ${ }^{16,17}$ MES-induced seizure is employed as a model for grand-mal epilepsy MES induced seizures can be prevented either by drugs that inhibit voltage dependant $\mathrm{Na}^{+}$channels such as phenytoin, valproate, felbamate and lamotrigine. Phenobarbitone antagonizes PTZ-induced seizure by enhancing GABA neurotransmission diazepam and phenobarbitone antagonizes PTZ-induced seizure by enhancing GABA neurotransmission.

Hence ethanolic extract of nardostachys jatamansi roots i.e. test compound may act in any of the following manner;

- Phenytoin like effect on voltage dependent sodium channels

- May block NMDA type excitatory amino acid receptors or increase synaptic norepinephrine levels.

- Can affect GABAergic neurotransmission, either by enhancing brain GABA levels or by altering the sensitivity of post synaptic GABA receptors

- By blocking T-type voltage dependent calcium channels.

By and large, the traditional system of medicine is slowacting as compared to the modern synthetic drugs because they are administered as crude preparations. A previous study has clearly shown that nardostachys jatamansi has an influence on the excitatory and inhibitory neurotransmission, of special interest being the increase in the gamma amino butyric acid (GABA) levels. ${ }^{17}$ Further study is required to confirm and isolate the active principle/principles that contributes to the anticonvulsant activity. The active principle/principles when isolated may prove to be a prospective broad spectrum anticonvulsant agent, either alone or in combination with already available anticonvulsant drugs. However, its long term effects have to be evaluated as convulsive disorders generally need prolonged therapy.

\section{CONCLUSION}

In conclusion, the result obtained from the present study suggests that the ethanolic extract of nardostachys jatamansi roots has anticonvulsant property which may be mediated by multiple mechanisms. The anticonvulsant activity of ethanolic extract of nardostachys jatamansi roots was less when compared to sodium valproate in maximal electro shock model. Whereas, in pentylenetetrazole induced seizure model, anticonvulsant activity of ethanolic extract of nardostachys jatamansi roots was comparable to sodium valproate.

\section{Funding: No funding sources}

Conflict of interest: None declared

Ethical approval: The study was approved by the Institutional Ethics Committee

\section{REFERENCES}

1. Acharya MM, Hattiangady B, Shetty AK. Progress in neuroprotective strategies for preventing epilepsy.Prog Neurobiol. 2008;84:363-404.

2. Saraf SA, Gupta R, Mishra A, Sharma AK, Punia RK. Advancements in traditional medicinal plants used in epilepsy. Phcog Rev. 2008;2:229-40.

3. Sander JWAS, Shorvon SD. Epidemiology of the epilepsies. J Neurol Neurosurg Psychiatry. 1996;61:433-43.

4. Banerjee TK, Ray BK, Das SK, Hazra A, Ghosal MK, Chaudhuri A, et al. A longitudinal study of epilepsy in Kolkota, India. Epilepsia. 2010;51:2384-91.

5. Smith MC, Bleck TP. Convulsive disorders: toxicity of anticonvulsants. Clinical Neuropharmacology. 1991;14:97-115.

6. Mattson RH. Efficacy and adverse effects of established and new antiepileptic drugs. Epilepsia. 1995;36(2):13-26.

7. Smith M, Wilcox KS, White HS. White discovery of antiepileptic drugs. Neurotherapeutics. 2007;4:12-7.

8. De Smet P. The role of plant derived drugs and herbal medicines in healthcare. Drugs. 1997;54:801.

9. Schachter SC. Botanicals and herbs: a traditional approach to treating epilepsy. Neurotherapeutics. 2009;6:415-20.

10. Subashini R, Gnanapragasam A, Senthilkumar S, Yogeeta S, Devaki T. Protective effect of Nardostachys jatamansi (Rhizomes) on mitochondrial respiration and lysosomal hydrolases during doxorubicin induced myocardial injury in rats. J Health Sci. 2007;53:67-72.

11. Ali S, Ansari KA, Jafry MA, Kabeer H, Diwakar G. Nardostachys jatamansi protects against liver damage induced by thioacetamide in rats. $\mathrm{J}$ Ethnopharm 2000;71:359-63.

12. Ahmad M, Yousuf S, Khan MB, Hoda MN, Ahmad AS, Ansari MS, et al. Attenuation by nardostachys jatamansi of 6-hydroxydopamine-induced parkinsonism in rats: behavioral, neurochemical, and immunohistochemical studies. Pharmacol Biochem Behav. 2006;83:150-60. 
13. OECD (2000) guidance document on acute oral toxicity. Environmental health and safety monograph series on testing and assessment no 24.

14. James JEP, James EP, Grey ME. Anticonvulsants In evaluation of drug activities pharmacometrics. Volume I. Laurence DR, Bacharahah ARI (Eds.). London. Academic press; 1964:287.

15. Rao VS, Rao A, Karanth KS. Anticonvulsant and neurotoxicity profile of nardostachys jatamansi in rats. Journal of Ethanopharmacology. 2005;102:351-6.
16. Rücker G, Tautges J, Sieck A, Wenzl H, Graf E. Isolation and pharmacodynamic activity of the sesquiterpene valeranone from Nardostachys jatamansi DC (in German). Arzneimittel forschung. 1978;28:7-13.

17. Prabhu V, Karanth KS, Rao Al. Effects of nardostachys jatamansion biogenic amines and inhibitory amino acids in the rat brain. Planta Med. 1994;60:114-7.

Cite this article as: Purushotham K, Basavanna PL. Anticonvulsant profile of nardostachys jatamansi roots in albino rats. Int $\mathrm{J}$ Basic Clin Pharmacol 2016;5:758-62. 